Jürg Kutter $\cdot$ Mahmut Ozsahin $\cdot$ Philippe Monnier

Roger Stupp

\title{
Combined modality treatment with full-dose chemotherapy and concomitant boost radiotherapy for advanced head and neck carcinoma
}

Received: 29 August 2003 / Accepted: 30 October 2003 / Published online: 5 March 2004

(C) Springer-Verlag 2004

\begin{abstract}
The purpose of this study was to evaluate the feasibility and efficacy of a treatment concept combining three cycles of full-dose chemotherapy (CT) with concomitant accelerated uninterrupted radiotherapy (RT). Twentythree patients (median age: 54 years, range: $35-70$ ) with locally advanced squamous cell carcinoma of the head and neck (SCCHN) were included. The primary tumor involved the hypopharynx $(n=7)$, base of the tongue $(n=10)$, nasopharynx $(n=2)$ or upper esophagus $(n=1)$ or its location was unknown $(n=3)$. Treatment consisted of three cycles of chemotherapy (cisplatin $100 \mathrm{mg} / \mathrm{m}^{2}$ on day $1 ; 5-\mathrm{FU}$ $1,000 \mathrm{mg} / \mathrm{m}^{2}$ per day for 5 days as a continuous infusion, preceded by amifostine $910 \mathrm{mg} / \mathrm{m}^{2}$ ), repeated every 3 weeks. Uninterrupted concomitant boost-accelerated RT (total dose of 70 Gy in 6 weeks) started together on day 1 of the second cycle. All but two patients received the full course of RT. Eighteen patients achieved complete remission (78\%). At a median follow-up of 45 months the overall survival was $56 \%$ (95\% c.i. $32-79 \%$ ) and the loco-regional control $71 \%$ (95\% c.i. 52-91\%). Toxicity involved reversible renal insufficiency of $\geq$ grade II in 9 patients (39\%) and neutropenic fever in 9 patients (39\%). All patients suffered from moderate to severe mucositis (grade II/III), and 19 patients presented cutaneous toxicity grade III. Concomitant boost-accelerated RT combined with concurrent full-dose cisplatin/5-FU chemotherapy and amifostine is feasible with manageable, although substantial, toxicity. The overall survival of 4 years is promising. Newer regi-
\end{abstract}

\footnotetext{
J. Kutter · P. Monnier

Department of Otorhinolaryngology and Head and Neck Surgery, University Hospital (CHUV), Lausanne, Switzerland

M. Ozsahin

Department of Radiation Oncology, University Hospital (CHUV), Lausanne, Switzerland

R. Stupp (舟)

Multidisciplinary Oncology Center, University Hospital (CHUV), 46 Rue du Bugnon, 1011 Lausanne, Switzerland

Tel.: +41-21-3140156, Fax: +41-21-3140737,

e-mail: Roger.Stupp@chuv.hospvd.ch
}

mens causing less acute mucosal and skin toxicity are needed.

Keywords Chemoradiotherapy - Head and neck cancer . Organ preservation $\cdot$ Amifostine $\cdot$ Base of the tongue

\section{Introduction}

Most patients with squamous cell carcinoma of the head and neck (SCCHN) present in a locoregionally advanced stage. Because of heavy exposure to alcohol and tobacco, many patients also suffer from chronic heart, lung and liver diseases, limiting treatment possibilities. Despite surgery and/or radiotherapy (RT), most patients with advanced disease (stage III and IV) will experience recurrences both with local and distant metastases, and overall survival for all causes remains poor [4, 8, 41, 47]. Furthermore, radical surgery for advanced disease is often mutilating, impairing organ function (speech, swallowing) and leading to social isolation $[14,52]$. Similarly, radiochemotherapy may be associated with significant late xerostomia and fibrosis, leading to nutritional difficulties and affecting the quality of life. Conventional RT (commonly 2 Gy/fraction, 70 Gy over 7 weeks) for unresectable disease is associated with a high locoregional failure rate. Furthermore, patients with advanced nodal disease are at high risk for distant metastases, and micrometastatic disease present at the time of diagnosis remains untreated by RT or surgery $[3,8,28]$.

Several advances have been made over the last decade. New surgical techniques, e.g., microvascular free tissue transfer, have allowed for less mutilating surgery, better organ function and more rapid recovery. Alternative fractionation schedules like concomitant boost-accelerated RT or hyperfractionated RT have shown improved local control and survival in comparison [16, 37]. Shortening the overall treatment time by accelerated fractionation will diminish the tumor cell repopulation in some tumors [18]. In the DAHANCA7 trial, treatment time was reduced by increasing the number of fractions per week from five to 
six, maintaining the overall treatment dose. Early toxicity was increased, but not late toxicity. Local control and survival were improved $[34,35]$.

Chemotherapy has consistently demonstrated responses in previously untreated patients. However, despite response rates exceeding $80 \%$, neoadjuvant chemotherapy has failed to improve overall survival in several randomized trials $[26,36]$. Nevertheless, patients treated with chemotherapy have a much lower incidence of developing distant metastases, and it may allow for organ preservation in twothirds of the patients with larynx and hypopharynx primaries [25, 27, 38, 48, 51].

By giving chemotherapy simultaneously with radiation, additional synergistic antitumoral activity may be gained. Chemotherapy will not only act on tumor cells outside the radiation field, but it will also induce additional cellular damage, thus limiting the cells possibility for repair [13, $42,46,50]$. Several randomized studies have shown an improved outcome with concomitant chemoradiotherapy $[6,9]$. The main limitation of concomitant chemoradiotherapy is increased acute toxicity, requiring frequent interruptions of radiotherapy or significant dose reductions in the chemotherapy. Prolonged breaks in radiotherapy and a longer overall treatment time may allow for tumor repopulation and thus the loss of the gained additional benefit, or it may even be detrimental $[15,18,45]$. Most concomitant chemoradiotherapy schemes administer only two cycles of a single agent chemotherapy together with standard fractionation radiotherapy. This may not be sufficient to control systemic disease and may reduce the incidence of distant metastases.

The aim of our treatment scheme was to deliver three cycles of a standard chemotherapy regimen together with an accelerated radiotherapy. A secondary goal was also to reduce the overall treatment time from diagnosis until the end of all therapy by limiting the duration without any therapy and beginning the first cycle of chemotherapy as soon as possible after diagnosis, thus using the time needed for RT planning and dental care for the administration of an initial cycle of chemotherapy.

\section{Subjects and methods}

Twenty-three consecutive patients with advanced stage and histologically confirmed squamous cell carcinoma of the head and neck were treated at the University Hospital of Lausanne (CHUV). Eligible patients had to have stage III or IV locally advanced disease; three patients with stage II disease were included to prevent them from having to undergo mutilating surgery (total glossectomy in two patients with base of tongue primaries and pharyngolaryngectomy with esophageal stripping in one patient with double primaries in the hypopharynx and esophagus). Tumors were classified according to the 1997 TNM classification [49] (Table 1). Pretreatment evaluation included panendoscopy (oro-pharyngo-laryngoscopy, bronchoscopy and esophagoscopy) in all but three patients (two patients with tumors located in the rhinopharynx and one patient with unknown primary and comorbidities not permitting general anesthesia). Imaging studies included a CT scan and/ or MRI at the primary site and neck, a chest X-ray and a CT of the chest and upper abdomen. A bone scan was performed in 16 patients $(70 \%)$. Baseline laboratory studies included blood chemistry (electrolytes, liver and kidney function tests) and a complete blood
Table 1 TNM classification

\begin{tabular}{lllll}
\hline & N0 & N1 & N2 & N3 \\
\hline Tx & - & - & 1 & 2 \\
T2 & 3 & 1 & 3 & - \\
T3 & 2 & 1 & 2 & 5 \\
T4 & 1 & 1 & 1 & - \\
\hline
\end{tabular}

count. All patients were seen and discussed at our multidisciplinary tumor board, and the treatment recommendation was made jointly by head and neck surgeons, radiation oncologists and medical oncologists with advice from the nursing staff, nutritionists and dentists. A port-a-cath (PAC) and percutaneous endoscopic gastrostomy (PEG) was routinely placed before or at the beginning of treatment in 19 and 21 out of the 23 patients, respectively. On the basis of our previous experience on early nutritional intervention, professional surveillance, advice and support were available during the entire treatment period [39]. Assistance for smoking and alcohol cessation was offered to all patients, including nicotine patches as indicated.

Toxicity was graded according to the Common Toxicity Criteria [11]. Response to treatment was defined as follows: complete response as the disappearance of all clinically and radiologically visible disease, partial response as a decrease of the product of the two largest perpendicular diameters by $\geq 50 \%$ and stable disease (non-response) as a decrease of $<50 \%$ or an increase of $<25 \%$. Survival was calculated according to the Kaplan-Meier method from the date of inclusion (tumor board decision) until the date of death or last follow-up [23]. The 95\% confidence intervals were calculated from standard errors (survival $\pm 1.96 \mathrm{SE}$ ). Event-free survival was calculated until progression, local recurrence or distant metastases, death of any cause or development of a second primary. The likelihood of local control without primary site surgery was considered censored at the time of patient death if no event had yet occurred. In the calculation of the overall survival with primary site preservation, only those patients who were alive with no primary site resection and with no residual or recurrent disease present at the primary site were considered censored. Patients with unknown primary (3) and nasopharynx primary (2) were excluded from the organ preservation analysis.

Patient characteristics are summarized in Table 2. There were 20 males and 3 women. The median age was 54 years (35-70 years). At the initial evaluation, the nutritional state was within normal limits in the majority of the patients [mean body mass index (BMI) 24.2 (normal: 18.5-24.9), range 18.7-32.3]. Primary tumor localization was the hypopharynx in seven patients, the base of the tongue in ten, the nasopharynx in two and unknown (with N3 neck disease) in three. One patient had an upper esophageal tumor with

Table 2 Patient and disease characteristics. * Includes one patient with a second primary in the hypopharynx, ${ }^{\mathrm{t}}$ includes one patient with a second primary in esophagus

\begin{tabular}{lll}
\hline No. of patients & & 23 \\
\hline Male: female & & $20: 3$ \\
Median age (range) & & 54 (35-70 years) \\
Localization & Rhinopharynx & 2 \\
& Base of the tongue* & 10 \\
& Hypopharynx ${ }^{\mathrm{t}}$ & 7 \\
& Esophagus & 1 \\
Stage & Unknown primary & 3 \\
& II & 3 \\
& III & 4 \\
& IV & 16 \\
\hline
\end{tabular}




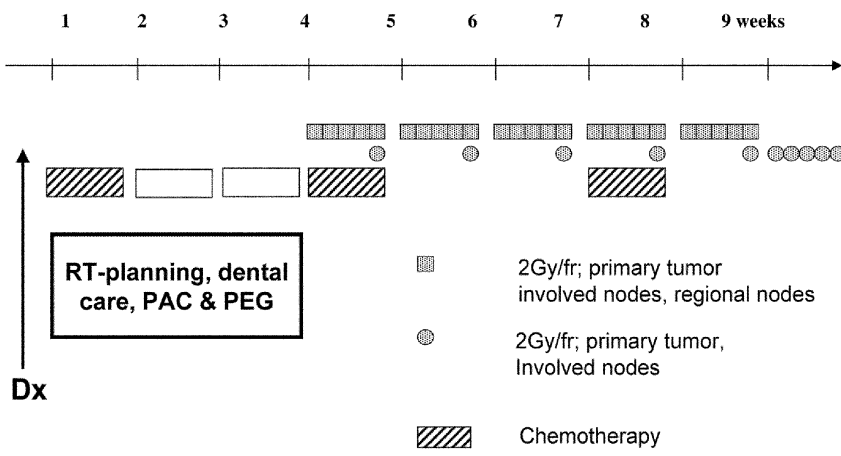

Fig. 1 Treatment concept. $D x$ diagnosis, $R T$ radiotherapy, $P A C$ porta-cath, $P E G$ percutaneous endoscopic gastrostomy, $f r$ fraction

posterior tracheal wall infiltration. Two patients had synchronous double primaries: a T2 hypopharyngeal carcinoma with a T1-cancer in the upper third of the esophagus and a T2 oropharyngeal carcinoma with a T1 supraglottic tumor. Seventy percent (16 patients) presented with stage IV and $13 \%$ (4 patients) with stage III disease. Three patients with stage II disease were also included, two base of the tongue primaries and one with two synchronous tumors. One patient had undergone a laser resection 1 year before inclusion in this study for a primary carcinoma in the oral cavity.

Our treatment concept called for a minimal delay by starting with the first cycle of chemotherapy as soon as possible after diagnosis (median time 19 days, range 12-49), while dental care as well as RT planning were still underway (Fig. 1). The second and third cycles of CT were planned during weeks 1 and 4 of radiation. CT consisted of cisplatin $\left(100 \mathrm{mg} / \mathrm{m}^{2}\right.$, day 1) and 5-fluorouracil $\left(1,000 \mathrm{mg} / \mathrm{m}^{2}\right.$ per day for 5 days as a continuous infusion). Amifostine $\left(910 \mathrm{mg} / \mathrm{m}^{2}\right)$ was administered immediately before cisplatin in order to reduce acute and late toxicity [7, 10,31, 40].

RT started together with the 1st day of the second CT cycle (day 22). We chose a moderately accelerated RT according to the DAHANCA 7 trial (70 Gy in 6 weeks) [34]. Six fractions (2 Gy each) a week in a monofractionated setting from Monday to Thursday and two fractions on Fridays (with an interval of $6 \mathrm{~h}$ between the two fractions) were given. 3-D conformal RT planning was used according to the ICRU 50 standards in all patients [22]. The clinical target volume (CTV) included the primary tumor as well as involved and regional lymph nodes (bilateral cervical and bilateral supraclavicular nodes in most patients). The planning target volume (PTV) included a 5-mm margin around the CTV in the three dimensions. Patient immobilization was realized using individualized thermoplastic immobilization masks in all patients. Irradiation was delivered by a telecobalt unit or a linear accelerator using photons (6 MV) and electrons. Intensity-modulated RT (IMRT) was not used. The PTV was irradiated to a total dose of $50 \mathrm{~Gy}$; the concomitant boost volume which included the primary tumor and involved nodes received a total dose of $70 \mathrm{~Gy}$ (second Friday dose during the first 5 weeks, and $5 \times 2$ Gy during the last treatment week).

Patients were seen by a medical oncologist and ENT surgeon weekly, and by a radiation oncologist during RT. Special advice and attention were given by the nursing team to skin care, and oral hygiene was enforced. Symptomatic treatment for mucositis (sodium bicarbonate) was offered and oral candidiasis promptly treated by fluconazol.

After treatment completion and after 2 months, the patients were reassessed at the neck and primary site by the same team. MRI, CT scan and biopsies were performed as indicated. Salvage surgery was performed if necessary. Patients were then followed by the ENT surgeon and radiation oncologist every 2 months for 2 years. At that time a panendoscopy was performed, and patients without evidence of disease subsequently were followed up every 6 months.
Table 3 Acute toxicity. $U L N$ upper limit of normal

\begin{tabular}{lllcc}
\hline & Cycle 1 & Cycle 2 & Cycle 3 & $\begin{array}{l}\text { No. of } \\
\text { patients }\end{array}$ \\
\hline Neutropenic fever & 1 & 4 & 4 & 9 \\
Creatinine (>1.5× ULN) & 2 & 5 & 4 & 9 \\
Mucositis (grade 3) & 1 & 6 & 21 & 21 \\
Dermatitis (grade 3) & 0 & 1 & 19 & 19 \\
Weight loss (>10\%) & 0 & 1 & 6 & 6 \\
\hline
\end{tabular}

\section{Results}

Twenty-three patients were enrolled and 21 patients (91\%) completed the therapy as planned. Median RT duration was 42 days (range 36-51). One patient died after the first CT cycle because of cardiac failure. One patient progressed rapidly during cycle 1 , and subsequently received palliative treatment only. One patient received only two cycles of CT because of acute toxicity (neutropenic fever, grade III mucositis and dermatitis).

\section{Toxicity}

Overall, 64 cycles of CT were administered. In three patients cisplatin had to be substituted by carboplatin because of renal insufficiency. A dose reduction of cisplatin was necessary in six patients for seven cycles $(11 \%)$. The administration of the third cycle was delayed in nine patients and omitted in one patient. The incidence and intensity of acute toxicity increased over treatment time (Table 3 ). Moderate and reversible renal insufficiency occurred in nine patients: grade II in $15 \%$ of the CT cycles and grade III in 3\%. Neutropenic fever was observed in nine patients $(39 \%)$ and in $15 \%$ of the cycles. It was more common in the evaluation period of cycle 2 and 3 (three and four patients, respectively) than during the initial CT cycle alone. One patient died 28 days after the end of treatment as the result of septicemia secondary to neutropenia.

All patients suffered from moderate to severe mucositis (grade II/III). Dermatitis at the end of treatment was common: two patients had grade II and 19 patients grade III. No surgical interventions were needed for sequelae. The main complaint at follow-up visits was mild to moderate (grade I/II) xerostomia in all patients.

\section{Supportive care}

The median weight change during therapy was $-8.6 \%$ of the initial weight (range +5.3 to $-15.9 \%$ ); six patients (29\%) had a weight loss of $>10 \%$ (grade 2). Twenty patients used PEG tubes. One patient had massive bleeding during the PEG placement and needed laparotomy for hemostasis. The median time of functional gastrostomy was 8.9 months. One patient had his PEG removed after 21 days because of infection. Only five patients were using it for 
more than 1 year. Prolonged hospitalization (more than 7 days per CT cycle) because of toxicity or general health status was necessary in 12 patients in order to improve supportive care measures.

\section{Response and survival}

At the end of the chemoradiotherapy, 18 patients achieved complete remission (78\%). One patient with partial remission in the neck was rendered disease free by surgery (neck dissection), and one patient with a base of the tongue primary was salvaged by total glossectomy and neck dissection. Two primarily inoperable patients, both with unknown primary and stage 4 disease, did not respond to therapy. With a median follow-up time of 45 months (range $0.6-63.4)$, overall survival at 4 years was $56 \%$ (95\% c.i. $32-79 \%$ ) (Fig. 2). Local control at 4 years was $84 \%$ (67$100 \%$ ) and locoregional control $71 \%$ (95\% c.i. $52-91 \%)$, respectively (Fig. 3). The event-free survival at 4 years was $50 \%$ (95\% c.i. 26-75\%), and the number of events was ten. Four patients experienced recurrence. One patient with an upper esophageal carcinoma had a local recurrence at 5 months; another local recurrence was observed in a patient with a hypopharynx primary at 34 months. One patient with a nasopharynx primary experienced recurrence in the neck after 11 months, and one patient with a hypopharynx tumor developed lung metastases 16 months after diagnosis. He was offered salvage treatment by further chemotherapy and surgery and died of a second nonsmall cell lung cancer primary 2 years later. The organ preservation rate was calculated for the 18 patients with base of the tongue, hypopharyngeal and upper esophageal primaries, excluding patients with unknown primaries and nasopharynx cancer. At 3 years, 13 out of 18 patients are alive with the organ in place (72\%). Two patients are still depending on PEG tubes for nutritional supplementation.

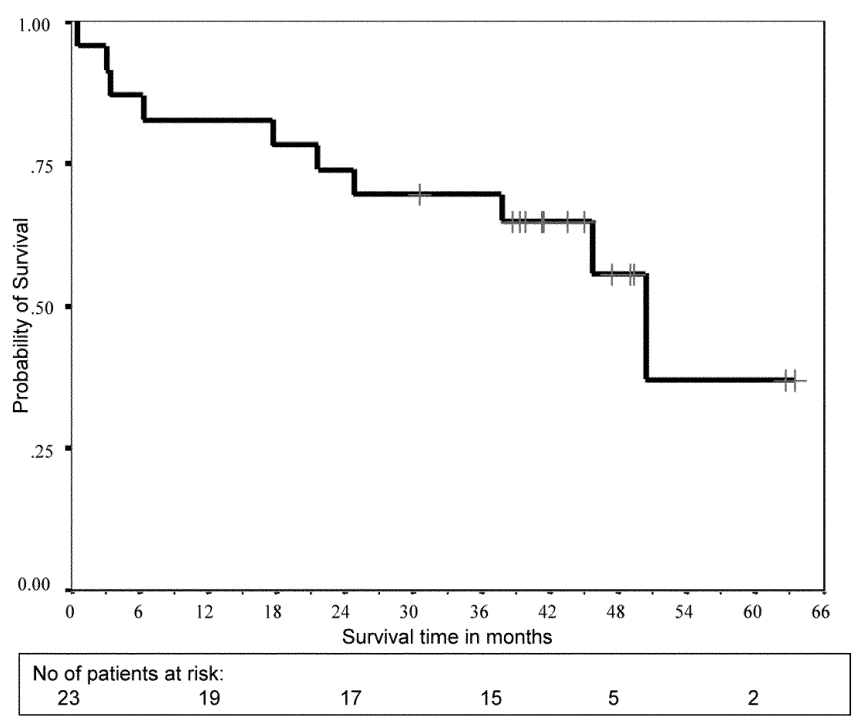

Fig. 2 Overall survival

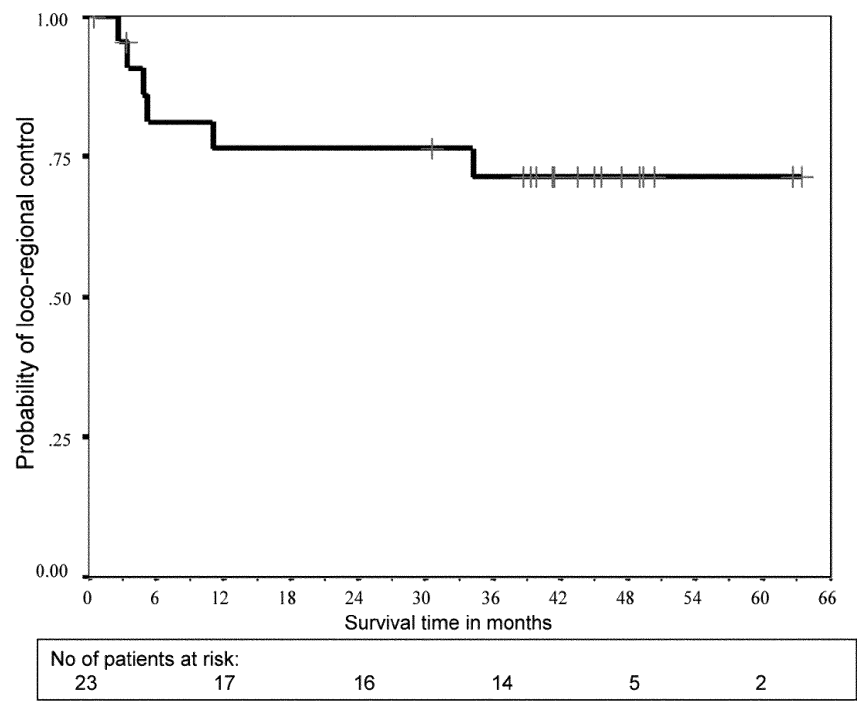

Fig. 3 Loco-regional control

\section{Discussion}

Our study shows that the concurrent administration of three cycles of full dose chemotherapy with cisplatin and 5-FU and concomitant boost-accelerated RT of $70 \mathrm{~Gy}$ is feasible in patients with advanced squamous cell carcinoma of the head and neck. Nevertheless, the acute toxicity of this regimen is substantial and requires close follow-up and supportive care by an experienced multidisciplinary team. Great emphasis was given to specialized and close nursing care, particularly in this group of patients known for frequent non-compliance. The main chemotherapy-induced toxicities were myelosuppression with neutropenic fever and renal insufficiency. Virtually all patients developed moderate to severe mucositis and dermatitis. However, with careful local care and nutrition via a nasograstic tube or PEG, the toxicity was manageable. In a similar study, Giralt et al. reported 59\% severe ( $\geq$ grade 3 ) mucositis and $14 \%$ severe skin reactions [17]. Despite their less intensive radiation regimen ( 60 Gy over 6.5 weeks, 1.8 Gy per fraction), acute toxicity was still substantial. In a randomized multicenter trial with hyperfractionated radiotherapy with and without concomitant cisplatin/5-FU at reduced doses, the incidence of severe mucositis was $77 \%$ in both groups, with an additional $22 \%$ of patients experiencing patchy (grade 2) mucositis [6]. A feeding tube was placed in 44 and $29 \%$ of patients with or without concomitant chemotherapy, respectively. Concomitant boost radiotherapy has been shown to improve locoregional control and is considered the standard irradiation scheme by the RTOG [16]. In their randomized trial, $86 \%$ of patients experienced grade 2 or 3 mucosal toxicity.

In our study less than $30 \%$ of the patients had at most a grade 2 weight loss of 10 to maximally $16 \%$. Some patients even gained weight during therapy. In comparison, Adelstein et al. administered two cycles of cisplatin/5-FU together with standard fractionated definitive RT. In this 
randomized study, comparing radiochemotherapy with radiation alone, feeding tubes were only placed as needed. Thirty percent of the patients in the RT-only group and $58 \%$ of the patients in the radiochemotherapy group required a feeding tube. Despite this, the mean weight loss was 6 and 12\%, respectively, with $70 \%$ of patients having a weight loss of $>10 \%$ in the radiochemotherapy group [1, 2]. Our policy of placing a feeding tube prophylactically together with ongoing counseling by a dietician may be the key to avoid malnutrition during treatment [39].

With the aim of reducing acute hematological toxicity, every chemotherapy cycle was preceded by a single dose of amifostine $[10,24]$. The contribution of only three amifostine doses cannot be assessed in this study, but appears to be of limited value. Administration of a lower dose of amifostine daily before RT has shown a modest decrease in the occurrence of late xerostomia; however, reduction of mucositis could only be demonstrated in a subgroup of patients with large radiation fields [5, 7]. Daily administration of i.v. amifostine before radiotherapy is costly, laborious and associated with nausea and occasional hypotension. Although a decrease in xerostomia has been shown [7], the efficacy of amifostine in reducing the incidence or severity of treatment-induced mucositis remains to be demonstrated in a prospective randomized trial.

All but one patient received three cycles of chemotherapy, although the third cycle had to be delayed or dose reduced in about half of the patients. No detrimental delays in radiation treatment due to toxicity were necessary in our study, while, despite a more gentle RT schedule, $42 \%$ of patients required a temporary interruption of RT in the study reported by Giralt [17].

Organ preservation with combined chemotherapy and radiation has been shown for larynx and hypopharynx cancer [27, 48]. In our study, we included ten patients with advanced base of tongue cancers, for which a surgical approach would have required total glossectomy. Only one of these patients subsequently required salvage surgery, and one is depending on the PEG for nutrition after 45 months. The other eight patients with base of tongue primaries have good organ function (voice and swallowing).

Concomitant chemoradiotherapy has been shown to be superior to radiotherapy alone in randomized trials. A metaanalysis suggests an absolute benefit of $8 \%$ with concomitant chemoradiotherapy [38]. In most studies, the chemotherapy dose has been reduced, and only one or two cycles were administered. Similarly, hyperfractionated and accelerated radiotherapy improved local control and survival in some randomized studies [16, 20, 21, 30, 43]. Two randomized studies compared hyperfractionated radiotherapy with the same RT and concomitant cisplatin/5FU chemotherapy and showed an improvement in local control and survival in the combined arm $[6,53]$. However, in one of the trials RT was given with planned treatment breaks during weeks 3 and 6 and in the other trial the chemotherapy was given at a considerably lower dose and with a longer interval between the treatment cycles. Compared with conventional RT alone, alternating chemoradiotherapy proved to be superior with a 5-year overall sur- vival of $24 \%$ compared to $10 \%$ for conventional $\mathrm{RT}$ in a study by Merlano [32, 33]. However, other studies did not demonstrate an improvement in survival when alternating chemoradiotherapy was compared to accelerated RT [12, 29]. In our study, accelerated concomitant boost radiation therapy was administered without additional breaks other than planned treatment-free days on weekends, and chemotherapy cycles could be delivered at the standard 2128-day intervals.

All of our patients presented with advanced disease, and surgical treatment would have been mutilating and would have impaired organ function. In this group of patients with poor prognosis, an overall survival of $56 \%$ at almost 4 years of follow-up is encouraging. Recurrences after more than 3 years are rare in this disease, and these patients can be considered cured from their primary tumor. It is of note that all the patients included in this protocol did not qualify for randomized multicenter cooperative group protocols because of the advanced stage, tumor localization or primary inoperability of their disease and thus represent a group of patients with particularly poor prognosis.

The concept of beginning chemotherapy immediately after diagnosis while radiotherapy planning is still underway, followed by definitive accelerated chemoradiotherapy, should be further explored. Although induction chemotherapy has not been shown to improve survival in many randomized trials $[19,44,48]$, the early introduction of therapy and the reduction of tumor volume before RT without prolonging overall treatment time may improve the outcome. Experienced multidisciplinary teams should deliver this type of therapy, and careful attention to supportive care measures is required. Despite a growing body of evidence for improved survival with concomitant chemoradiotherapy, acute toxicity remains the main obstacle for the wide acceptance of this treatment modality. New treatment regimens with less toxicity (i.e., IMRT) are warranted.

\section{References}

1. Adelstein DJ, Saxton JP, Lavertu P, Tuason L, Wood BG, Wanamaker JR, Eliachar I, Strome M, Van Kirk MA (1997) A phase III randomized trial comparing concurrent chemotherapy and radiotherapy with radiotherapy alone in resectable stage III and IV squamous cell head and neck cancer: preliminary results. Head Neck 19:567-575

2. Adelstein DJ, Lavertu P, Saxton JP, Secic M, Wood BG, Wanamaker JR, Eliachar I, Strome M, Larto MA (2000) Mature results of a phase III randomized trial comparing concurrent chemoradiotherapy with radiation therapy alone in patients with stage III and IV squamous cell carcinoma of the head and neck. Cancer 88:876-883

3. Alvi A, Johnson JT (1997) Development of distant metastasis after treatment of advanced-stage head and neck cancer. Head Neck 19:500-505

4. Amdur RJ, Mendenhall WM, Stringer SP, Villaret DB, Cassisi NJ (2001) Organ preservation with radiotherapy for T1-T2 carcinoma of the pyriform sinus. Head Neck 23:353-362 
5. Bourhis J, De Crevoisier R, Abdulkarim B, Deutsch E, Lusinchi A, Luboinski B, Wibault P, Eschwege F (2000) A randomized study of very accelerated radiotherapy with and without amifostine in head and neck squamous cell carcinoma. Int J Radiat Oncol Biol Phys 46:1105-1108

6. Brizel D, Albers M, Fisher S, Scher R, Richtsmeier W, Hars V, George S, Huang A, Prosnitz L (1998) Hyperfractionated irradiation with or without concurrent chemotherapy for locally advanced head and neck cancer. N Engl J Med 338:1798-1804

7. Brizel DM, Wasserman TH, Henke M, Strnad V, Rudat V, Monnier A, Eschwege F, Zhang J, Russell L, Oster W, Sauer R (2000) Phase III randomized trial of amifostine as a radioprotector in head and neck cancer. J Clin Oncol 18:3339-3345

8. Brockstein B, Haraf D, Kies M, Stenson K, Mittal B, Pelzer H, Vokes E (2000) Distant metastases after concomitant chemoradiotherapy for head and neck cancer: Risk is dependent upon pretreatment lymph node stage. Proc Am Soc Clin Oncol 19 (abstract 1635):414a

9. Browman GP, Hodson DI, Mackenzie RJ, Bestic N, Zuraw L (2001) Choosing a concomitant chemotherapy and radiotherapy regimen for squamous cell head and neck cancer: A systematic review of the published literature with subgroup analysis. Head Neck 23:579-589

10. Buntzel J, Kuttner K, Frohlich D, Glatzel M (1998) Selective cytoprotection with amifostine in concurrent radiochemotherapy for head and neck cancer. Ann Oncol 9:505-509

11. Common Toxicity Criteria, version 2.0 (1999), vol 1999. Cancer Therapy Evaluation Program

12. Corvo R, Benasso M, Sanguineti G, Lionetto R, Bacigalupo A, Margarino G, Pallestrini E, Merlano M, Vitale V, Rosso R (2001) Alternating chemoradiotherapy versus partly accelerated radiotherapy in locally advanced squamous cell carcinoma of the head and neck: results from a phase III randomized trial. Cancer 92:2856-2867

13. de Serdio JL, Villar A, Martinez JC, Perez MD, Martin JJ, Fuentes C, Gil-Curbelo J, Hernandez R, Suner M, Espineira M, Artazkoz JJ, Saavedra JA (1998) Chemotherapy as a part of each treatment fraction in a twice-a-day hyperfractionated schedule: a new chemoradiotherapy approach for advanced head and neck cancer. Head Neck 20:489-496

14. Eckel HE, Staar S, Volling P, Sittel C, Damm M, Jungehuelsing M (2001) Surgical treatment for hypopharynx carcinoma: feasibility, mortality, and results. Otolaryngol Head Neck Surg 124:561-569

15. Fowler JF, Lindstrom MJ (1992) Loss of local control with prolongation in radiotherapy. Int J Radiat Oncol Biol Phys 23: 457-467

16. Fu KK, Pajak TF, Trotti A, Jones CU, Spencer SA, Phillips TL, Garden AS, Ridge JA, Cooper JS, Ang KK (2000) A Radiation Therapy Oncology Group (RTOG) phase III randomized study to compare hyperfractionation and two variants of accelerated fractionation to standard fractionation radiotherapy for head and neck squamous cell carcinomas: first report of RTOG 9003. Int J Radiat Oncol Biol Phys 48:7-16

17. Giralt JL, Gonzalez J, del Campo JM, Maldonado J, Sanz X, Pamias J, Eraso A, Bescos S, Raspall G (2000) Preoperative induction chemotherapy followed by concurrent chemoradiotherapy in advanced carcinoma of the oral cavity and oropharynx. Cancer 89:939-945

18. Hansen O, Overgaard J, Hansen HS, Overgaard M, Hoyer M, Jorgensen KE, Bastholt L, Berthelsen A (1997) Importance of overall treatment time for the outcome of radiotherapy of advanced head and neck carcinoma: dependency on tumor differentiation. Radiother Oncol 43:47-51

19. Head and Neck Contracts Program (1987) Adjuvant chemotherapy for advanced head and neck squamous carcinoma. Final report. Cancer 60:301-311
20. Horiot JC, Le Fur R, N'Guyen T, Chenal C, Schraub S, Alfonsi S, Gardani G, Van Den Bogaert W, Danczak S, Bolla M, Van Glabbeke M, De Pauw M (1992) Hyperfractionation versus conventional fractionation in oropharyngeal carcinoma: Final analysis of a randomized trial of the EORTC cooperative group of radiotherapy. Radiother Oncol 25:231-241

21. Horiot JC, Bontemps P, Begg AC, Le Fur R, Van Den Bogaert W, Bolla M, N'Guyen T, Van Den Weijngaert D, Bernier J, Lusinchi A, Stuschke D, Lopez Torrecilla D, Jancar B, Collette L, Van Glabbeke M, Pierart M (1996) Hyperfractionated and accelerated radiotherapy in head and neck cancer: results of the EORTC trials and impact on clinical practice. Bull Cancer Radiother 83:314-320

22. ICRU (1993) Prescribing, recording and reporting photon beam therapy. Report 50, Bethesda

23. Kaplan E, Meier P (1958) Nonparametric estimation from incomplete observations. J Am Stat Assoc 53:487-481

24. Kemp G, Rose P, Lurain J, Berman M, Manetta A, Roullet B, Homesley H, Belpomme D, Glick J (1996) Amifostine pretreatment for protection against cyclophosphamide-induced and cisplatin-induced toxicities: results of a randomized control trial in patients with advanced ovarian cancer. J Clin Oncol 14:2101-2112

25. Kim S, Wu HG, Heo DS, Kim KH, Sung MW, Park CI (2001) Advanced hypopharyngeal carcinoma treatment results according to treatment modalities. Head Neck 23:713-717

26. Laramore GE, Scott CB, Al-Sarraf M, Haselow RE, Ervin TJ, Wheeler R, Jacobs JR, Schuller DE, Gahbauer RA, Schwade JG, Campbell BH (1992) Adjuvant chemotherapy for resectable squamous cell carcinomas of the head and neck: Report on intergroup study 0034. Int J Radiat Oncol Biol Phys 23:705713

27. Lefebvre J, Chevalier D, Luboinski B, Kirkpatrick A, Collette L, Sahmoud T, for the EORTC Head and Neck Cooperative Group (1996) Larynx preservation in pyriform sinus cancer: preliminary results of a European Organization for Reserach and Treatment of Cancer phase III trial. J Natl Cancer Inst 88: 890-899

28. Leon X, Quer M, Orus C, del Prado Venegas M, Lopez M (2000) Distant metastases in head and neck cancer patients who achieved loco-regional control. Head Neck 22:680-686

29. Leyvraz S, Pasche P, Bauer J, Bernasconi S, Monnier P (1994) Rapidly alternating chemotherapy and hyperfractionated radiotherapy in the management of locally advanced head and neck carcinoma: 4-year results of a phase I/II study. J Clin Oncol 12: $1876-1885$

30. Marcial VA, Pajak TF, Chu C, et al (1987) Hyperfractionated photon radiation therapy in the treatment of advanced squamous cell carcinoma of the oral cavity, pharynx, larynx, and sinuses, using radiation therapy as the only planned modality: preliminary report by the Radiation Therapy Oncology Group (RTOG). Int J Radiat Oncol Biol Phys 13:41-47

31. Mehta MP (1999) Amifostine and combined-modality therapeutic approaches. Semin Oncol 26:95-101

32. Merlano M, Vitale V, Rosso R, Benasso M, Corvo R, Cavallari M, Sanguineti G, Bacigalupo A, Badellino F, Margarino G, Brema F, Pastorino G, Marziano C, Grimaldi A, Scasso F, Sperati G, Pallestrini E, Garaventa G, Accomando E, et al. (1992) Treatment of advanced squamous-cell carcinoma of the head and neck with alternating chemotherapy and radiotherapy. N Engl J Med 327:1115-21

33. Merlano M, Benasso M, Corvo R, Rosso R, Vitale V, Blengio F, Numico G, Margarino G, Bonelli L, Santi L (1996) Fiveyear update of a randomized trial of alternating radiotherapy and chemotherapy compared with radiotherapy alone in treatment of unresectable squamous cell carcinoma of the head and neck. J Natl Cancer Inst 88:583-589 
34. Overgaard J, Sand Hansen H, Overgaard M, Bashtholt L, Specht L, Evensen J, Pedersen M, Grau C, Jørgensen K, Hansen O, Sapru W, Berthelsen A (1997) Conventional radiotherapy as primary treatment of squamous cell carcinoma of the head and neck. A randomized multcenter study of 5 versus 6 fractions per week - report from the DAHANCA 7 trial (abstract no. 106). Int J Radiat Oncol Biol Phys 39 [Suppl]:188

35. Overgaard J, Alsner J, Eriksen J, Horsman MR, Grau C (2000) Importance of overall treatment time for the response to radiotherapy in patients with squamous cell carcinoma of the head and neck. Rays 25:313-319

36. Paccagnella A, Orlando A, Marchiori C, Zorat PL, Cavaniglia G, Sileni VC, Jirillo A, Tomio L, Fila G, Fede A, Endrizzi L, Bari M, Sampognaro E, Balli M, Gava A, Pappagallo GL, Fiorentino MV (1994) Phase III trial of initial chemotherapy in stage III or IV head and neck cancers: a study by the Gruppo di Studio sui Tumori della Testa e del Collo. J Natl Cancer Inst 86:265-272

37. Peters LJ (1992) Accelerated fractionation using the concomitant boost: a contribution of radiobiology to radiotherapy. BJR [Suppl] 24:200-203

38. Pignon JP, Bourhis J, Domenge C, Designe L (2000) Chemotherapy added to locoregional treatment for head and neck squamous-cell carcinoma: three meta-analyses of updated individual data. MACH-NC Collaborative Group: Meta-Analysis of Chemotherapy on Head and Neck Cancer. Lancet 355:949_ 955

39. Piquet M, Ozsahin M, Larpin I, Zouhair A, Coti P, Monney M, Monnier P, Mirimanoff R, Roulet M (2002) Early nutrional intervention in orophayngeal cancer patients undergoing radiotherapy. Support Care Cancer 10:502-504

40. Planting AS, Catimel G, de Mulder PH, de Graeff A, Hoppener F, Verweij J, Oster W, Vermorken JB (1999) Randomized study of a short course of weekly cisplatin with or without amifostine in advanced head and neck cancer. EORTC Head and Neck Cooperative Group. Ann Oncol 10:693-700

41. Poulsen MG, Denham JW, Peters LJ, Lamb DS, Spry NA, Hindley A, Krawitz H, Hamilton C, Keller J, Tripcony L, Walker Q (2001) A randomised trial of accelerated and conventional radiotherapy for stage III and IV squamous carcinoma of the head and neck: a Trans-Tasman Radiation Oncology Group Study. Radiother Oncol 60:113-122

42. Rudat V, Wannenmacher M (2001) Role of multimodal treatment in oropharynx, larynx, and hypopharynx cancer. Semin Surg Oncol 20:66-74
43. Sanchiz F, Milla A, Torner J, Bonet F, Artola N, Carreno L, Moya LM, Riera D, Ripol S, Cirera L (1990) Single fraction per day versus two fractions per day versus radiochemotherapy in the treatment of head and neck cancer. Int $\mathbf{J}$ Radiat Oncol Biol Phys 19:1347-1350

44. Schuller DE, Metch B, Mattox D, Stein D, McCracken JD (1988) Prospective chemotherapy in advanced head and neck cancer: Final report of the Southwest Oncology Group. Laryngoscope 98:1205-1211

45. Skladowski K, Law MG, Maciejewski B, Steel GG (1994) Planned and unplanned gaps in radiotherapy: the importance of gap position and gap duration. Radiother Oncol 30:109-120

46. Stupp R, Vokes EE (1995) Progress in treatment of head and neck cancer, part 2, chemoradiotherapy. Strahlenther Onkol 171:140-148

47. Stupp R, Chung T, Collins S, Dougherty M, Weichselbaum R, Vokes E (2000) Head and neck. In: Abeloff M, Armitage J, Lichter A, Niederhuber J (eds) Clinical oncology. Churchill Livingstone, Philadelphia, pp 1248-1316

48. The Department of Veterans Affairs Laryngeal Cancer Study Group (1991) Induction chemotherapy plus radiation compared with surgery plus radiation in patients with advanced laryngeal cancer. N Engl J Med 324:1685-1690

49. TNM classification of malignant tumours (1997) Wiley-Liss, New York

50. Vokes EE, Weichselbaum RR (1990) Concomitant chemoradiotherapy: rationale and clinical experience in patients with solid tumors. J Clin Oncol 8:911-934

51. Vokes EE, Mick R, Lester EP, Panje WR, Weichselbaum RR (1991) Cisplatin and fluorouracil chemotherapy does not yield long-term benefit in locally advanced head and neck cancer: results from a single institution. J Clin Oncol 9:1376-1384

52. Ward EC, Bishop B, Frisby J, Stevens M (2002) Swallowing outcomes following laryngectomy and pharyngolaryngectomy. Arch Otolaryngol Head Neck Surg 128:181-186

53. Wendt T, Grabenbauer G, Rödel C, Thiel H, Aydin H, Rohlof R, Wustrow T, Iro H, Popella C, Schallhorn A (1998) Simultaneous radiochemotherapy versus radiotherapy alone in advanced head and neck cancer: a randomized study. J Clin Oncol 16: 1318-1324 